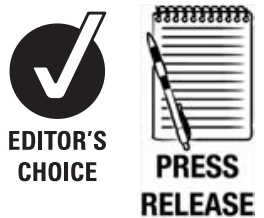

${ }^{1}$ Centre for Burden of Disease and Cost-Effectiveness,

School of Population Health,

The University of Queensland, Brisbane, Australia

${ }^{2}$ Cancer Prevention Research Centre, School of Population Health, The University of Queensland, Brisbane,

Australia

${ }^{3}$ Baker IDI Heart and Diabetes Institute, Melbourne, Australia

\section{Correspondence to}

$J$ Lennert Veerman, Centre

for Burden of Disease and

Cost-Effectiveness, School

of Population Health, The

University of Queensland,

Herston Road, Herston, OLD

4006, Australia;

I.veerman@uq.edu.au

Accepted 12 May 2011

\title{
Television viewing time and reduced life expectancy: a life table analysis
}

\author{
J Lennert Veerman, ${ }^{1}$ Genevieve N Healy, ${ }^{2,3}$ Linda J Cobiac, ${ }^{1}$ Theo Vos, \\ Elisabeth A H Winkler, ${ }^{2}$ Neville Owen, ${ }^{2,3}$ David W Dunstan ${ }^{3}$
}

\begin{abstract}
Background Prolonged television (TV) viewing time is unfavourably associated with mortality outcomes, particularly for cardiovascular disease, but the impact on life expectancy has not been quantified. The authors estimate the extent to which TV viewing time reduces life expectancy in Australia, 2008.
\end{abstract}

Methods The authors constructed a life table model that incorporates a previously reported mortality risk associated with TV time. Data were from the Australian Bureau of Statistics and the Australian Diabetes, Obesity and Lifestyle Study, a national population-based observational survey that started in 1999-2000. The authors modelled impacts of changes in population average TV viewing time on life expectancy at birth.

Results The amount of TV viewed in Australia in 2008 reduced life expectancy at birth by 1.8 years $(95 \%$ uncertainty interval (UI): 8.4 days to 3.7 years) for men and 1.5 years (95\% UI: 6.8 days to 3.1 years) for women. Compared with persons who watch no TV, those who spend a lifetime average of $6 \mathrm{~h} /$ day watching TV can expect to live 4.8 years (95\% Ul: 11 days to 10.4 years) less. On average, every single hour of TV viewed after the age of 25 reduces the viewer's life expectancy by 21.8 (95\% UI: 0.3-44.7) min. This study is limited by the low precision with which the relationship between TV viewing time and mortality is currently known.

Conclusions TV viewing time may be associated with a loss of life that is comparable to other major chronic disease risk factors such as physical inactivity and obesity.

\section{INTRODUCTION}

Sedentary behaviour (too much sitting, as distinct from too little exercise), assessed as either daily sitting time, ${ }^{1}$ leisure-time sitting, ${ }^{2}$ time spent sitting in cars $^{3}$ or television (TV) viewing time ${ }^{4-6}$ is associated with higher mortality risk - particularly from cardiovascular disease. Of these sedentary behaviours, TV viewing time is the most commonly examined. ${ }^{7}$ This leisure-time behaviour is ubiquitous (the average adult in the USA, eg, spends $35.5 \mathrm{~h} /$ week watching TV), ${ }^{8}$ and is unfavourably associated with several cardiometabolic biomarkers. ${ }^{9}{ }^{10}$ However, the impact of TV viewing time on life expectancy has not been quantified. We estimate the extent to which TV viewing time reduces life expectancy.

\section{METHODS}

We constructed a simple life table model using previously published findings on the relationship between TV viewing time and mortality from analyses of the Australian Diabetes, Obesity and Lifestyle Study (AusDiab) and Australian population and mortality data. ${ }^{411-13}$

\section{The Australian Diabetes, Obesity and Lifestyle Study}

AusDiab was a national population-based crosssectional observational survey conducted in 1999 2000 with 11247 participants aged $\geq 25$ years (mean age 50 years). Over $85 \%$ of the sample was born in Australia, New Zealand or the UK, and over $94 \%$ spoke English as their first language. Using a reliable and valid measure, ${ }^{7}$ participants reported the total time they spent watching TV or videos in the previous week, when it was their main activity. Figure 1 presents mean TV viewing by age in the Australian population (with data weighted to match the age and sex distribution of the 1998 estimated residential population of Australia aged $\geq 25$ years).

\section{TV viewing time and mortality}

Using AusDiab data, Dunstan et al previously reported a deleterious relationship between TV viewing time and all-cause mortality (median follow-up 6.6 years) in the 8800 participants with complete data (3846 men, 4954 women). ${ }^{4}$ Following adjustment for age, gender, leisuretime exercise, waist circumference, smoking, education, total energy intake, alcohol intake, diet quality, hypertension, total cholesterol, HDL cholesterol, serum triglycerides, lipid-lowering medication use, previously reported cardiovascular disease and glucose tolerance status, each additional hour of TV viewing time per day was associated with an $8 \%$ increased risk for all-cause mortality (hazard ratio (HR) 1.08 (95\% CI: 1.00 to 1.17); $\mathrm{p}=0.048)$.

Associations between risk factors and mortality typically weaken with increasing age. ${ }^{14}$ Accordingly, we used an age-attenuation in the HR, which we based on the age effects observed by the Prospective Studies Collaboration, ${ }^{14}$ assuming the strength of the relationship between TV viewing and mortality declines linearly with age, and adjusted to ensure a total TV-related mortality identical to that observed by Dunstan et al in deriving the overall HR.

\section{Life table model}

In the model, we compared the life table for the Australian population from age 25 years (assuming current rates of TV viewing: figure 1) with a 
life table for an identical population that watches no TV. We adopted a 'period' interpretation of the life table in which the hypothetical birth cohort experiences current rates of mortality and TV viewing (or no TV viewing) over their lifetime. We adjusted the rates of mortality in the life table for the population that watches no TV, using the following formula:

$$
M^{\prime}=M \times \exp (\ln (\mathrm{HR} \times A))^{-T V}
$$

where:

$M$ is the all-cause mortality, by age and gender, for the Australian population in $2008^{13}$;

$\mathrm{M}^{\prime}$ is the all-cause mortality, by age and gender, for an identical population that watches no TV;
HR denotes the hazard ratio for the effect of TV viewing on all-cause mortality ${ }^{4}$;

$A$ is the age-attenuation factor based on the Prospective Studies Collaboration trend ${ }^{14}$ and

TV is the average daily number of hours of TV currently viewed, by age and gender, in Australia (figure 1).

Calculations were performed in MS Excel (Microsoft Corporation, Redmond, Washington, USA). Uncertainty was assessed by Monte Carlo simulation using the Ersatz program (Epigear.com, Brisbane, Australia; 100000 iterations), assuming a log-normal distribution of the HR and a normal distribution of average daily TV viewing time.

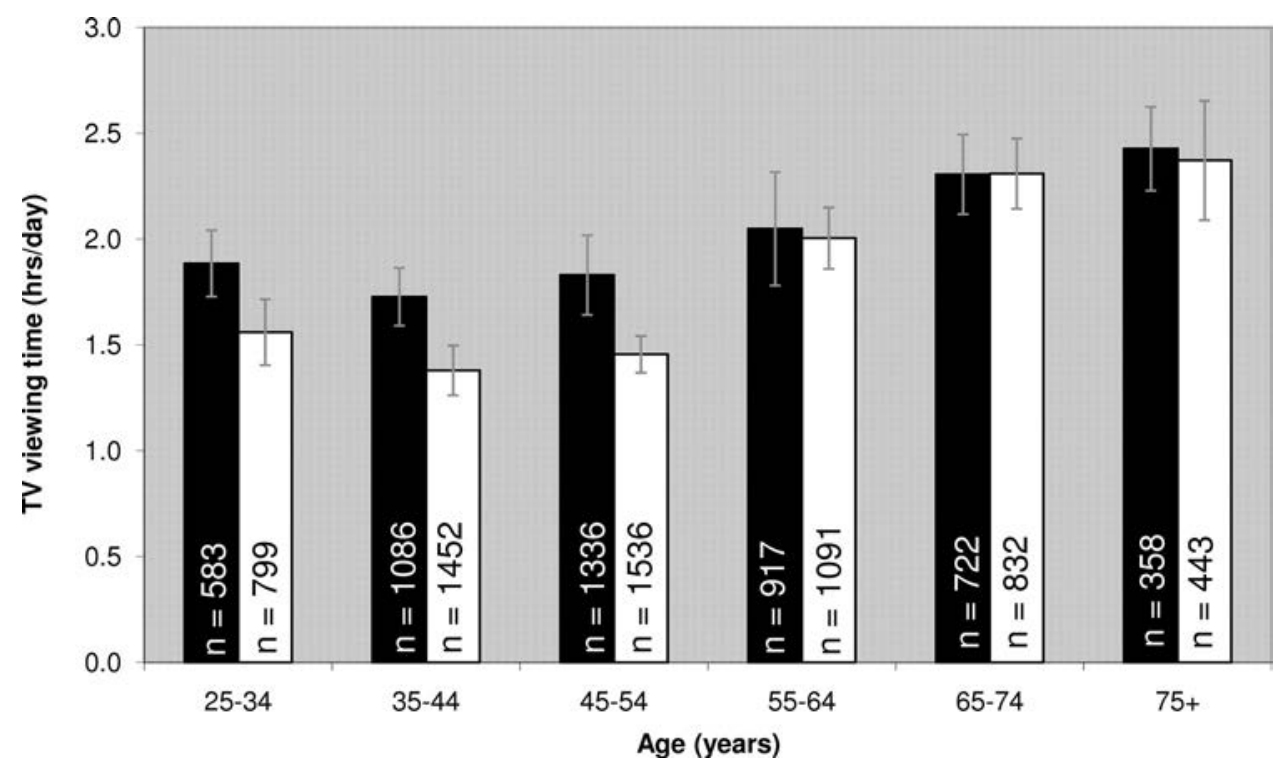

Figure 1 Average daily hours of TV viewing by age and gender in Australia, 1999-2000. Based on data from the AusDiab study, weighted to the total Australian population, 1998. Men in black, women in white; error bars denote SEs.

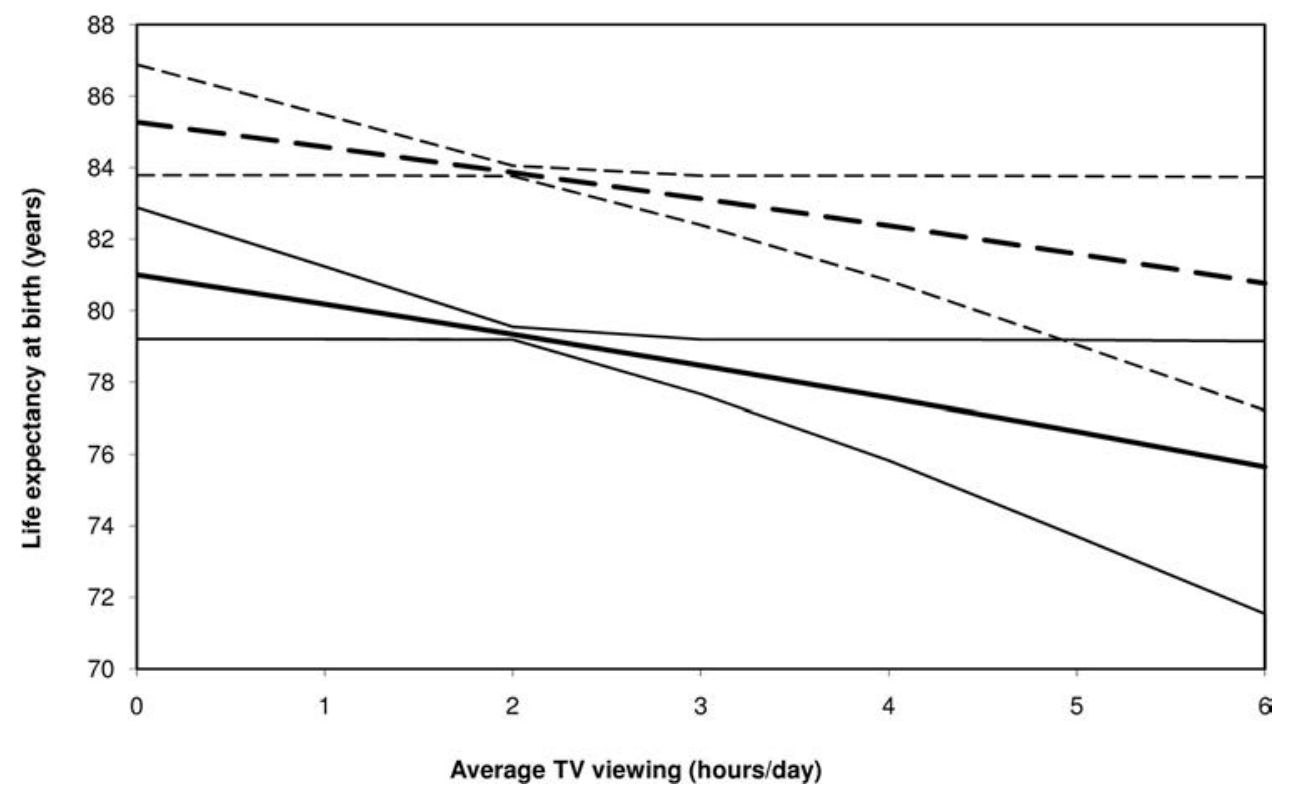

Figure 2 Life expectancy at birth by average daily amount of TV viewing time. Men in continuous lines and women in dashed lines; means (bold) and $95 \%$ uncertainty intervals. 


\section{RESULTS}

Australians aged 25 and older watched a total of 9.8 billion hours of TV in 2008. Our estimates indicate these hours of TV viewing were associated with a loss of 286000 (95\% uncertainty interval (UI): 4000-547 000) life years for the Australian population in 2008 , assuming a stationary population with no trends in life expectancy or TV viewing time. Without TV viewing, the 2008 life expectancy at birth of Australian men and women would have been 1.8 years (95\% UI: 8.4 days to 3.7 years) and 1.5 years (95\% UI: 6.8 days to 3.1 years) higher than observed. Every single hour of TV viewed after the age of 25 reduces the viewer's life expectancy by 21.8 (95\% UI: 0.3-44.7) min. An Australian who spends a lifetime average of $6 \mathrm{~h} /$ day watching TV (ie, in the top 1\% of population TV viewing) can expect to live 4.8 years ( $95 \%$ UI: 11 days to 10.4 years) less than a person who does not watch TV (figure 2).

\section{DISCUSSION}

These findings suggest that substantial loss of life may be associated with prolonged TV viewing time among Australian adults. This is the first study to estimate the loss of life from this ubiquitous sedentary behaviour, both at the level of individuals and a whole population. While we used Australian data, the effects in other industrialised and developing countries are likely to be comparable, given the typically large amounts of time spent watching TV and similarities in disease patterns.

The HR from the source study (AusDiab) may have been an underestimate due to random measurement error in TV viewing time (regression dilution bias). ${ }^{15}$ However, our model does not include time lags and treats TV viewing behaviour as stable over time, whereas Australian data show time spent in leisuretime electronic media use has increased from $1.5 \mathrm{~h} /$ day in 1992 to $2.1 \mathrm{~h} /$ day in 1997 and $2.2 \mathrm{~h} /$ day in $2006 .{ }^{16}$ If there are time lags in the effects of TV viewing time on mortality, our results may have been slightly overestimated. Consistent with Australia as the setting for this study, we based the association between TV viewing time and mortality on Australian findings. ${ }^{4}$ The 95\% UIs for the estimates are very wide, but our findings are supported by two comparable studies that estimated the association between TV viewing and mortality. Stamatakis et al used data from Scotland and found a 7\% increase in all-cause mortality risk per daily hour of TV time (HR 1.07 (95\% CI: 1.03 to 1.11)). ${ }^{6}$ Using data from England, Wijndaele et al estimated that each additional hour per day of TV viewing increased the risk by 4\% (HR 1.04 (95\% CI: 1.01 to 1.09$)) .{ }^{5}$ This latter association is half as strong as the one we used in this study and, consequently, its use would approximately halve the effects presented here. But that is still a sizeable effect, and the difference between the HRs found may partly be due to a less stringent definition of 'watching' TV used by Wijndaele et al, which might have included time with the TV on during other activities. This would dilute the association with mortality. The higher average age of their study population may also play a role, given that the association between risk factors and mortality tends to weaken with age. ${ }^{14}$

If these HRs are confirmed, and shown to reflect a causal association, TV viewing is a public health problem comparable in size to established behavioural risk factors. In the Framingham Heart study, low physical activity levels led to a loss of about 1.4 years compared with moderate physical activity levels, and 3.6 years compared with high levels of physical activity, after age $50 .{ }^{17}$ Using life expectancy at age 50 , our model suggests that similar losses in life expectancy might be associated with watching about 2.1 and $5.4 \mathrm{~h}$ of TV viewing a day, respectively. In men and women aged 50 and older in Framingham, obesity (vs normal weight) was associated with a loss of 1.3 and 1.0 years, respectively. ${ }^{18}$ This compares to the effect of 1.9 and $1.6 \mathrm{~h}$ of TV viewing per day. Lifelong smoking was associated with a loss of life, after age 50 , of 4.3 years for men and 4.1 years for women, ${ }^{18}$ which equates to 6.0 and 6.4 daily hours of TV in our model. The average loss of life due to the smoking of a single cigarette has been estimated at 11 min, ${ }^{19}$ though this may be an underestimate. ${ }^{20}$ Our findings suggest that half an hour of TV viewing above age 25 may shorten life to a similar degree.

Because TV viewing is a ubiquitous behaviour that occupies significant portions of adults' leisure time, ${ }^{8}$ its effects are significant for overall population health. In the Australian Burden of Disease Study, physical inactivity was estimated to cause a loss of 117000 life years in 2003, which would translate to 127000 life years in 2008, adjusting for population size. ${ }^{21}$ This is well under this study's best estimate of the burden associated with TV viewing of 286000 life years. The latter burden is larger than that due to obesity, which cost 99000 life years in 2003 (109000 in 2008), and may even surpass that due to tobacco (178 000 in 2008). ${ }^{21}$ Sociodemographic groups among whom high TV viewing time is more prevalent (those with less than tertiary education, living outside of state capital cities and/or having no paid employment) are particularly at risk. ${ }^{22}$

In conclusion, TV viewing time may have adverse health consequences that rival those of lack of physical activity, obesity and smoking; every single hour of TV viewed may shorten life by as much as $22 \mathrm{~min}$. Further study is required to confirm this, and to specify the link of TV viewing time (and other common sedentary behaviours such as workplace sitting and time spent in cars) with mortality. The Australian and US guidelines for children recommend no more than $2 \mathrm{~h}$ of screen time/day. ${ }^{23} 24$ With further corroborative evidence, a public health case could be made that adults also need to limit the time spent watching TV.

Acknowledgements The authors would like to thank Dr Elizabeth L M Barr of the Baker IDI Heart and Diabetes Institute for her contribution to the manuscript.

Funding JLV was supported by an NHMRC Capacity building grant (\#456002). The contributions of NO, GNH and EAHW were supported by a Program Grant (\#569940) from the National Health and Medical Research Council (NHMRC) of Australia and by Research Infrastructure funding from Queensland Health. GNH is also supported by an NHMRC (\#569861)/National Heart Foundation of Australia (PH 08B 3905) Postdoctoral Fellowship. DWD is supported by a Victorian Health Promotion Foundation Public Health Research Fellowship. The authors are most grateful to the following for their support of the AusDiab study: The Commonwealth Department of Health and Aged Care, Abbott Australasia, Alphapharm, AstraZeneca, Aventis Pharmaceutical, Bristol-Myers Squibb Pharmaceuticals, Eli Lilly (Aust), GlaxoSmithKline, Janssen-Cilag (Aust), Merck Lipha s.a., Merck Sharp \& Dohme (Aust), Novartis Pharmaceutical (Aust), Novo Nordisk Pharmaceutical, Pharmacia and Upjohn, Pfizer, Roche Diagnostics, Sanofi Synthelabo (Aust), Servier Laboratories (Aust), BioRad Laboratories, HITECH Pathology, the Australian Kidney Foundation, Diabetes Australia, Diabetes Australia (Northern Territory), Queensland Health, South Australian Department of Human Services, Tasmanian Department of Health and Human Services, Territory Health Services and Victorian Department of Human Services and Health Department of Western Australia. Also, for their invaluable contribution to the setup and field activities of AusDiab, the authors are enormously grateful to A Allman, B Atkins, S Bennett, S Chadban, S Colagiuri, M de Courten, M Dalton, M D'Embden, T Dwyer, D Jolley, I Kemp, P Magnus, J Mathews, D McCarty, A Meehan, K O'Dea, P Phillips, P Popplewell, C Reid, J Shaw, A Stewart, R Tapp, H Taylor, T Welborn, F Wilson and P Zimmet.

Competing interests All authors have completed the Unified Competing Interest form at http://www.icmje.org/coi _ disclosure.pdf. 


\section{What is already known on this topic}

Accumulating evidence makes increasingly clear that sedentary behaviour (too much sitting, as distinct from too little exercise), assessed as daily sitting time, leisure-time sitting, time spent sitting in cars or television viewing time, is associated with higher mortality risk - particularly from cardiovascular disease.

\section{What this study adds}

Though the current evidence base does not permit precise estimates, this life table analysis shows that TV viewing is associated with losses of life expectancy that may be comparable in size to those related to physical inactivity and obesity.

Contributors All authors had full access to the data in the study. JLV takes responsibility for the integrity of the data and the accuracy of the data analysis. He is guarantor. JLV and GNH designed the study. GNH, DWD, NO, JLV and LJC acquired the data. JLV, EAHW, LJC and GNH performed the analysis and interpreted the data. JLV drafted the manuscript, which was critically revised for intellectual content by all co-authors.

Provenance and peer review Not commissioned; externally peer reviewed.

\section{REFERENCES}

1. Katzmarzyk PT, Church TS, Craig CL, et al. Sitting time and mortality from all causes, cardiovascular disease, and cancer. Med Sci Sports Exerc 2009;41:998-1005.

2. Patel AV, Bernstein L, Deka A, et al. Leisure time spent sitting in relation to total mortality in a prospective cohort of US adults. Am J Epidemiol 2010;172:419-29.

3. Warren TY, Barry V, Hooker SP, et al. Sedentary behaviors increase risk of cardiovascular disease mortality in men. Med Sci Sports Exerc 2010;42:879-85.

4. Dunstan DW, Barr EL, Healy GN, et al. Television viewing time and mortality: the Australian Diabetes, Obesity and Lifestyle Study (AusDiab). Circulation 2010;121:384-91.

5. Wijndaele $\mathbf{K}$, Brage $\mathrm{S}$, Besson $\mathrm{H}$, et al. Television viewing time independently predicts all-cause and cardiovascular mortality: the EPIC Norfolk study. Int J Epidemiol 2011;40:150-9.

6. Stamatakis E, Hamer M, Dunstan DW. Screen-based entertainment time, allcause mortality, and cardiovascular events: population-based study with ongoing mortality and hospital events follow-up. J Am Coll Cardiol 2011;57:292-9.
7. Clark BK, Sugiyama T, Healy GN, et al. Validity and reliability of measures of television viewing time and other non-occupational sedentary behaviour of adults: a review. Obes Rev 2009;10:7-16.

8. Nielsen Company. Three Screen Report: Television, Internet and Mobile Usage in the US. Vol 8. 1st Quarter, 2010.

9. Dunstan DW, Salmon J, Healy GN, et al. Association of television viewing with fasting and 2-h postchallenge plasma glucose levels in adults without diagnosed diabetes. Diabetes Care 2007;30:516-22.

10. Healy GN, Dunstan DW, Salmon J, et al. Television time and continuous metabolic risk in physically active adults. Med Sci Sports Exerc 2008;40:639-45.

11. Dunstan DW, Zimmet PZ, Welborn TA, et al. The Australian Diabetes, Obesity and Lifestyle Study (AusDiab)-methods and response rates. Diabetes Res Clin Pract 2002:57:119-29.

12. Australian Bureau of Statistics. 3222.0 - Population Projections, Australia, 2006 to 2101. ABS, 2008. http://www.abs.gov.au/AUSSTATS/abs@.nsf/ DetailsPage/3222.02006\%20to\%202101?0penDocument laccessed 4 May 2011).

13. Australian Bureau of Statistics. 3302.0 - Deaths, Australia, 2008. ABS, 2009 http://www.abs.gov.au/ausstats/abs@.nsf/Products/C9E6832AA7C7AD92CA25 76780025B579?opendocument (accessed 4 May 2011).

14. Prospective Studies Collaboration. Age-specific relevance of usual blood pressure to vascular mortality: a meta-analysis of individual data for one million adults in 61 prospective studies. Lancet 2002;360:1903-13.

15. MacMahon S, Peto R, Cutler J, et al. Blood pressure, stroke, and coronary heart disease. Part 1, Prolonged differences in blood pressure: prospective observational studies corrected for the regression dilution bias. Lancet 1990;335:765-74.

16. Australian Bureau of Statistics. 4153.0 - How Australians Use Their Time, 2006. Canberra: ABS, 2008

17. Franco $\mathbf{O H}$, de Laet C, Peeters A, et al. Effects of physical activity on life expectancy with cardiovascular disease. Arch Intern Med 2005;165:2355-60.

18. Nusselder WJ, Franco $\mathrm{OH}$, Peeters $\mathrm{A}$, et al. Living healthier for longer: comparative effects of three heart-healthy behaviors on life expectancy with and without cardiovascular disease. BMC Public Health 2009;9:487.

19. Shaw M, Mitchell R, Dorling D. Time for a smoke? One cigarette reduces your life by 11 minutes. BMJ 2000;320:53.

20. Doll R, Peto R, Boreham J, et al. Mortality in relation to smoking: 50 years' observations on male British doctors. BMJ 2004;328:1519.

21. Begg S, Vos T, Barker B, et al. The Burden of Disease and Injury in Australia 2003 Canberra:Australian Institute of Health and Welfare, 2007.

22. Clark BK, Sugiyama T, Healy GN, et al. Socio-demographic correlates of prolonged television viewing time in Australian men and women: the AusDiab study. J Phys Act Health 2010;7:595-601.

23. American Academy of Pediatrics. Committee on Public Education. American Academy of Pediatrics: children, adolescents, and television. Pediatrics 2001;107:423-6.

24. Commonwealth of Australia and Department of Health and Ageing. Australia's Physical Activity Recommendations for Children and Young People. Canberra:Department of Health and Ageing, 2004. 


\section{Corrections}

Veerman JL, Healy GN, Cobiac LJ, et al. Television viewing time and reduced life expectancy: a life table analysis. Br J Sports Med 2012;46:927-30. This was published in the print issue with the incorrect doi 10.1136/bjsports-2011-085662. The correct doi is 10.1136/bjsm.2011.085662 because this is the doi it was originally published with Online First.

Br J Sports Med 2012;46:1144. doi:10.1136/bjsm.2011.085662 